\title{
Book review: Seeing Lithics: A Middle-range Theory for Testing for Cultural Transmission in the Pleistocene
}

\author{
Katie Davenport-Mackey
}

School of Archaeology and Ancient History, University of Leicester, University Road, Leicester, Leicestershire, LE1 7RH, U.K. and Lithoscapes Archaeological Research Foundation, Rose House, Mellguards, Southwaite, Carlisle, Cumbria, CA4 0LE, U.K. Email: km203@leicester.ac.uk; katie@lithoscapes.co.uk

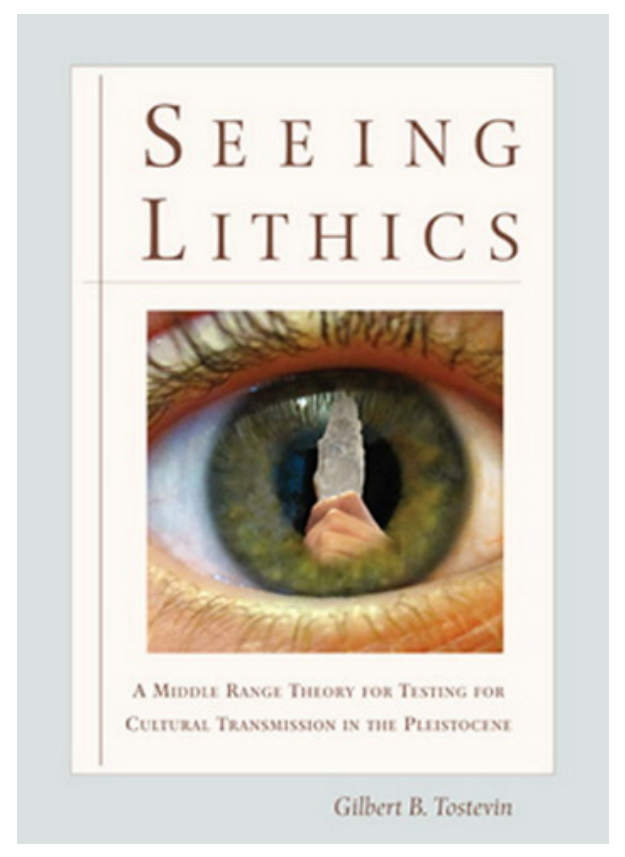

Seeing Lithics: A Middle-range Theory for Testing for Cultural Transmission in the Pleistocene by Gilbert Tostevin

Oxbow Books, 2013, pp. 608. ISBN 978-184-217-527-9

http://www.oxbowbooks.com/oxbow/seeing-lithics.html

Seeing Lithics represents a doctoral thesis submitted to Harvard University by Gilbert Tostevin in 2000. Tostevin is currently a professor of Anthropology at the University of Minnesota and has written extensively on human evolution, lithic technology, Old World archaeology, and Palaeolithic archaeology. These interests can be clearly seen in this book which develops a new theoretical and analytical approach to the study of cultural transmission in the Middle-Upper Palaeolithic transition.

Published by the School of History, Classics and Archaeology, University of Edinburgh ISSN: 2055-0472. URL: http://journals.ed.ac.uk/lithicstudies/

This work is licensed under a Creative Commons Attribution 2.5 UK: Scotland License. 
The book is divided into a total of 9 chapters. Chapter 1 introduces the study of the Middle-Upper Palaeolithic transition and emphasises the need for a middle range theory connecting the archaeological record and cultural transmission theory. This is necessary due to the difficulty of inferring behavioural interaction and technological transfer between modern humans and Neanderthals from fossil evidence. Chapter 2 introduces the sampling criteria used in the study of 18 lithic assemblages from Central Europe, Eastern Europe, and the Levant. Chapter 3 combines various theoretical perspectives (e.g., cultural transmission theory, social intimacy, taskscape visibility) in a conceptual framework for inferring symmetric (transfer from parents to offspring) and asymmetric (diffusion through intermediaries) transmission from lithics. Tostevin expects different levels of social intimacy to be reflected in blank production and tool-kit morphology, since the former takes place at residential sites with high levels of social intimacy, while the latter are manufactured, used, and abandoned across the landscape in circumstances of low social intimacy. Chapter 4 presents the attributes of tactical and strategic flint knapping behaviours that may be influenced by cultural transmission. These are derived from various experimental studies (e.g., experimental archaeology, fracture studies, VDFlaker). Chapters 5, 6, and 7 present the similarities and differences in blank production and tool-kit morphology within and between the 3 regions and Chapter 8 compares the earliest assemblage with the first non-Middle Palaeolithic assemblage within and between the different areas. Tostevin concludes that a cultural transmission event (the "Bohunician behavioural package") occurred during the Middle-Upper Palaeolithic transition since blank production is similar, but there is a lack of antecedents in all three regions. Chapter 9 suggests that the Bohunician behavioural package may be the result of symmetric transmission between modern humans. The book includes an appendix of lithic illustrations, an extensive bibliography, and a useful index.

This book represents an attempt to develop a procedure for examining, inferring, and testing cultural transmission in lithics that avoids some of the historical problems associated with typological and technological analysis. However, a number of methodological and theoretical problems arise from the use of such an innovative approach. The methodological issues relate to the use of certain attributes (e.g., cross-section and profile) that are notoriously difficult to measure reliably and the separation of the chaîne opératoire into different flint knapping domains. While the division of the chaîne opératoire into the production of blanks and the use of tools represents a useful model, it does not take into account the complexities of reuse and recycling of lithics. The theoretical issue concerns the case to abandon formal typologies which hide the range of variation in lithics under broad categories. Even though the quantitative analysis of continuous variation among lithic attributes is important for the future development of classification, the rejection of typology is problematic for two main reasons: 1 . It makes it more difficult to interpret the data. 2. It makes the study incompatible with previous studies. In summary, this book makes an original and significant contribution to knowledge and understanding of the Middle-Upper Palaeolithic transition, but the results are difficult to verify and compare. 